\title{
Prototype Semantic Analysis of Abstract and Concrete Concepts Among Jordanian and American Students
}

\author{
Mohammad Al-Ajaleen (Corresponding author) \\ Department of Linguistics, Faculty of Foreign Languages \\ University of Jordan, Amman, Jordan
}

Tel: 962-772-205-298Ｅ-mail: mohammadajaleen1984@gmail.com

Rajai Al-Khanji

Department of Linguistics, Faculty of Foreign Languages

University of Jordan, Amman, Jordan

Received: February 14, 2020

Accepted: March 1, 2020

Published: March 18, 2020

doi:10.5296/ijl.v12i2.16468

URL: https://doi.org/10.5296/ijl.v12i2.16468

\begin{abstract}
The aim of the present study was to investigate the extent to which culture may play a role in constructing the prototypical structure of every daily life concepts. Two concepts were investigated in this study: an abstract concept (freedom) and a concrete concept (drinks). The sample of the study comprised two distinct cultures, Jordanians and Americans, who are undergraduate students. To come up with the findings, the researchers carried out two experiments. The first experiment aimed at examining the impact of culture on generating semantic features and examples of the target concepts. The second one investigated the effect of culture on rating the prototypicality of the generated features and examples. To answer the first research question, the researcher calculated the frequency and the percentage of each response. The researcher used the SPSS to answer the second research question. The researcher used the t-test for independent samples (Jordanians and Americans) to calculate the means and the standard deviations in order to examine any possible significant differences that may result from cultural difference. Briefly, the findings showed that culture affected, to a considerable extent, the processes of generating and prototypicality rating of the examples and features of the target concepts.
\end{abstract}

Keywords: Prototype structure, Prototypicality ratings, Features generating 


\section{Introduction}

Evans (2007) argues that cognitive linguistics is a branch of cognitive science that emerged in the 1960s and 1970s. According to Evans, cognitive linguistics is a tridimensional approach examining the relationship between language, the human mind, and socio-physical experience. However, cognitive linguistics is the umbrella under which two sub-fields fall. These two well-developed fields are "cognitive semantics" and "cognitive grammar." The present study is mainly concerned with cognitive semantics.

According to Tamly (2000: 4), using the word semantics with the word cognitive evokes the conceptual content of the meaning as well as its organization in language. In a nutshell, the conceptual content includes the ideational content and the experiential content. Evans and Green (2006:156) consider cognitive semantics an ideal approach to linguistic meaning that addresses it as manifestations of conceptual structure. What they mean by conceptual structure is "the nature and organization of mental representation in all its richness and diversity." They explain that this approach enables us to examine the relationship between the daily-life experience, the conceptual system, and the semantic structure encoded by language.

This study is concerned with one of the most basic phenomena of the conceptual system in particular and the cognitive semantics in general which is categorization. Before digging deeper into this conceptual process, let us consider the following illustrative situation. Imagine that you came into a library, where many books and documents were put on the tables and you were asked for help to classify and put them on shelves. What would you do In this case? Simply, you would classify them in terms of the fields they belong to. For example, you would collect and catalogue the linguistic books together in their proper place. You would also assort these books according to the subfields of linguistics they belong to such as phonology, syntax, semantics, psycholinguistics, etc. This simple example may widen our imagination to think of the categorization process as one of the most pervasive phenomenon in daily life activities.

The process of categorization is the essence of the prototype theory which was proposed by Rosch in the mid-1970s. This theory had its origins in philosophy, and then was extended to cognitive linguistics by scholars interested in studying the interaction between language and cognition like Fillmore (1976), Lakoff (1987), and Talmy (2000). The prototype theory is a reaction against the classical theory, which was first appeared in the work of Plato, who tried to group things, based on their features. According to Mervis and Rosch (1981), in the classical view, meanings of concepts are defined by a set of necessary and sufficient features, which are binary in nature (i.e., presence [+] and absence [-]). Thus, to be a member of a certain category, an item must have all the features that define this category. Briefly, membership is a matter of all-or-nothing. To clarify, through his example, Saeed (1997: 35) provides a blocked fixed boundary definition for the concept "woman" by virtue of a bundle of features such as, human, adult, female and married. Saeed claims that any concept must carry all these features to be an example of the category woman.

The prototype theory came to reduce the rigorous status of the classical theory. In this regard, Rosch (1998) confirms the validity of the principle "fuzziness of meanings and boundaries". 
She explains that members of a certain category share a set of features where some members might be identical because they hold the same attributes; some members might be similar because they carry similar attributes and others are dissimilar. Thus, it can be argued that the prototype theory rejects the idea of relying on necessary and sufficient conditions to define concepts' meanings and categories' boundaries. Instead, it supports fuzziness of concepts' meaning and fuzziness of categories' boundaries (Mervis \& Rosch, 1981). Meanings constructions and categorizations process are matters of conceptualization that happen in the minds of language users (Evans, 2007: 363). For example, let us consider the potential meanings of the concept beach. The best dictionary definition for this concept could be 'the rocky or sandy land next to the sea'. Yet, beach may also carry a diverse range of positive associations like leisure, comfort, volleyball, swimming, etc, or it may carry negative associations like boat accident, drowning, shark attack, etc. The diversity in these associations can be attributed to the divergence of conceptual structures in the minds of language users which is shaped by interacting with the world (Evans \& Green, 2006: 156).

The prototype theory respects the principle of graded membership which presupposes the nonequivalence status of category members. Additionally, it does not completely deny the role of the defining features in determining meanings of some concepts along with their categories. In this respect, Cruse (2000: 130-132) argues that features are implicitly found in our minds. These features contribute to building up images of central prototypes which can be used as a point of reference to determine the status of other examples belonging to a given concept. For example, imagine you were asked to decide whether or not the tuk-tuk (a three-wheel wagon used to transport in some south Asian countries) is an example of the category vehicle, especially it is not used in your environment and you do not know much about it. In this case, you would start thinking of its features and compare them to the features of any optimal vehicle you know such as a car. Conversely, people who live in South Asian countries (as used as in India) may answer the same question more quickly because this transport vehicle (i.e. tuk-tuk) is very popular in their countries. This example leads us to confirm that members do not necessarily represent the category they belong to equally, at least under the effect of some factors such as culture.

The present study is mainly concerned with the process of categorization; it investigates the impact of culture on the prototypicality ratings examples and features belonging to two concepts, one concrete concept (drinks) and one abstract concept (freedom). These concepts were chosen out of a long list of concepts, because they are assumed to be presented differently in the minds of people from different cultural background. The participants in this study are from two different cultural backgrounds (i.e., Jordanians and Americans).

\subsection{Statement of the Problem}

After reviewing several studies in the field of prototype theory, the researcher has noticed that the vast majority of these studies were applied to western cultures (Fehr \& Russell 1984; Aitchison 1998; Basile 2007; Sprecher 2009; Harasymchuk\& Fehr 2011; Birnie-Porter \&Lydon 2012). This study attempts to investigate the effect of culture on the rating process through comparing two different cultures, the Jordanian culture and the American culture. 


\section{MlMacrothink}

International Journal of Linguistics

ISSN 1948-5425

2020, Vol. 12, No. 2

Thus, it aims to investigate how participants of different cultures conceptualize concepts and rate the degrees of the representation of examples and features belonging to these concepts.

\subsection{Purpose of the Study}

The present study seeks to answer the following two questions:

1. To what extent does the cultural difference between Jordanians and Americans affect the process of generating members and features of abstract and concrete concepts?

2. To what extent does the cultural difference between Jordanians and Americans affect the prototypicality rating of concepts' members and features?

\subsection{Significance of the Study}

Though many studies have been conducted about the rating process of category members and features within the framework of the prototype theory, the majority of these studies focus on psychological aspects and personal relationships (Padua, 1998; Kearns and Fincham, 2004; Fehr and Sprecher, 2009; Neto and Mullet, 2014). Alongside this line of thought, the significance of this study lies in some facets. Firstly, this study focuses on the cognitive account of concept's meaning and categorization. It supports the claim of the cognitive semantics which states that meaning of entities lies in the mind of language users (i.e. conceptual meaning), and that language itself does not encode meaning. Secondly, to the researcher's best knowledge, there is a scarcity of studies within the prototype theory framework in the entire Arab region in general and Jordan in particular. Finally, this study might be significant because it compares two distinct cultures which in turn may enrich the literature with the role of culture on shaping the meaning of the concepts in the world.

\subsection{Limitations of the Study}

There are some limitations that should be highlighted in this study. Firstly, the findings of the study cannot be generalized to all Jordanians and Americans. Admittedly, in addition to the existence of several cultures across the American states, the number of respondents is reasonably small. This may raise the question of whether a larger or a different group may lead to different results. Secondly, this study is also limited to the concepts under investigation. That is, investigating new concepts may produce different results. Finally, although the researcher have tried to introduce culture as an external factor that may affect the prototypicality rating process, inevitably there are more factors to be explored such as gender and age.

\section{Literature Review}

\subsection{Studies on Concrete Concepts}

Ashcraft (1978) conducted a study to examine the role of "features dominance" and "features overlap" in determining the prototypicality (i.e., goodness of exemplar) of members belonging to some categories. He attempted to reveal the semantic relatedness between these members and the categories to which they belong. In his study, he provided three typical members and three atypical members for each one of 17 concrete categories, namely 
beverage, bird, building, cloth, clothing, fish, flower, fruit, furniture, insect, mammal, musical instrument, tools, tree, vegetable, vehicle, and weapon. According to Ashcraft (1978: 27 ), the term "property dominance" refers to the production frequency of features generated to define categories. He adds that the frequency ratio of features explicates the semantic relatedness between categories and their properties, and between categories and their members. The results of Ashcraft's study revealed that the production frequency average of a category's features was significantly higher for typical members than atypical members. Additionally, the features overlap among categories and their typical members were significantly higher than among categories and their atypical members.

Schwanenflugel and Rey (1986) conducted a study aiming at investigating the impact of culture familiarity, especially the intercultural familiarity, on the ratings of the typicality of 12 categories. Two monolingual Floridian groups participated in the study, a Spanish group and an English group. Although, the two groups speak two different languages, and they are supposed to share the same culture because they live in the same territory, as it is provided by the researchers. Despite the divergence in listing members for the target categories, the results of the study showed that there is general agreement among the two groups on the prototypicality ratings of the members of each category. This similarity in ratings is justified because, as it is stated by Schwanenflugel and Rey, the two samples are of the same culture----that is, they live in the same particular area, South Florida, as well as sharing the same traditions and the daily-life experiences. The results revealed interesting indices about the impact of cultural similarity in determining the degree of representation of the members to their categories

The notion of investigating the prototypicality ratings in regard to more diverse cultures caught the attention of some researchers (Lin and Schwanenflugel, 1995). They conducted a study as a reaction against Schwanenflugel and Rey (1986) who underrated the role of cultural differences by investigating two samples of the same culture. In their study, Lin and Schwanenflugel (1995) studied two different cultures, the American culture and the Chinese culture. The sample consisted of two groups, thirty Chinese speakers living in Taiwan and thirty English speakers living in the United States. Each cultural group was provided with 10 categories with their examples and was asked to rate how prototypical these examples are to each category. Two supplementary groups representing the two cultures also rerated the typicality of the same examples of each category. In other words, in addition to the cross-cultural rating, the purpose of including intercultural groups was to investigate what is called "cultural familiarity" in the rating process. Thus, the researchers examined the impact of the cultural similarity by comparing the results of the two groups in each culture, and then they investigated the cross-cultural effect by comparing the results of the first two groups from each culture. The results revealed a notable correlation of cultural familiarity with prototypical structure in each culture, with superiority of the American groups over the Chinese groups. The results also showed that there was great variation in the prototypicality rating between the cross-cultural groups (the Americans and the Chinese participants).

Basile's study (2007) investigated the role of culture in determining the prototypicality ratings of members of four concrete categories: vehicles, clothes, vegetables, and furniture. The 
participants in the study represent two cultures, the European culture and the North American culture. The total number of the participants was 20, 10 Europeans (from Belgium, France, Germany, Spain, and Norway) and 10 North Americans (from Canada and USA). The participants were asked to determine the degree of typicality of each category's members using a seven-point-scale in which Point 1 represents the prototypical example(s) and Point 7 represents the most peripheral example(s) of the category, or even a non-member of the category. The results revealed that the two cultural groups showed different responses. Basile (2007:31) argued that it is not easy to justify these results, but she suggests that the participants' responses might be affected by their daily-life experiences.

Wang, et al., (2016) investigated the categorization of some items in light of what is called "the typicality effect." The typicality effect declares that a typical item is more quickly retrieved from memory and more easily assigned as a member of a given category than an atypical one. Two samples participated in this study, 16 participants for the inclusion sample and 16 for the exclusion sample. The participants were provided with six examples belonging to one category. Further, a seventh example was also provided. This seventh example could be a typical member of the category, it could be an atypical one, or even it could be a non-member of the category. The task of the inclusion group was to judge as fast as possible whether the seventh example shares the feature(s) available in the other six examples. Conversely, the task of the exclusion group was to quickly decide whether the seventh example is a member of the category or not. The data were collected through behavioral and event-related potential (ERP). The study revealed two interesting results: (1) the two groups showed the same degree of accuracy in response to the task; and (2) participants in the inclusion group took less time judging typical members than participants judging atypical members in the exclusion group

\subsection{Studies on Abstract Concepts}

"Emotion" was the first abstract concept to be investigated from a prototypical perspective. Fehr and Russell (1984: 464) argued that because the concept emotion cannot be classically defined, it is hard to find a commonly accepted definition for it. Instead, it can be best understood through the prototype perspective. Accordingly, this motivated Fehr and Russell to carry out three experiments to examine the concept of "emotion" within the prototype framework. In the first experiment, they asked a group of undergraduate students at the University of British Columbia, Canada, to list as many examples and types of emotion as could come to their minds. The researchers chose only twenty items from the list to use in further experiments in the same study. The distribution of the items was as follow: ten items with the highest frequency in the list and ten with various degrees of frequency. In the second experiment, another group of participants was provided with the twenty chosen items and was asked to name the superordinate category to which each one belongs. The aim of this experiment was to support the prototypical structure of the concept "emotion" by confirming the subordination of these items to the superordinate category. In the third experiment a third group of students were asked to rate the prototypicality of each item on six-point scale ranging from 1 (an extremely poor example of emotion) to point 6 (an extremely good example of emotion). The results advocated for the prototypical structure of the concept 
emotion and showed a list of good examples of the concept of "emotion," namely love, hate, sadness, happiness, anger, fear, joy, depression, guilt and excitement.

Along the same line, Fehr (1986) wrote a PhD thesis on two subcategories of the concept of "emotion," namely love and commitment. This study aimed to examine the prototypical structure of love and commitment, as well as interpreting the relationship between these two concepts. Three experiments were carried out to achieve this purpose. The first experiment was about generating features of the two target concepts; the second one addressed the prototypicality ratings of the generated features, whereas the third was about features recall. Generally speaking, the results showed that, despite the relatedness of these two concepts, still, they are distinct. The results of the first experiment showed that, although there was some overlapping between the features of love and commitment, participants were able to provide some other distinctive features for each category. The result of the second experiment showed adequate agreement among participants on what could be good or poor features of each concept. Additionally, there was a correlation between the frequency of features listing and the centrality rating. In the last experiment, it was found that the participants were able to remember the central features (i.e., good) more than peripheral features (i.e., poor) of each concept. This memory task reveals that laymen can recall good exemplars of categories more quickly than poorer ones.

Kearns and Fincham (2004) argued that despite the existence of several definitions for forgiveness in the literature, the best way to understand this concept is through studying it from a prototypical perspective. Kearns and Fincham followed the common procedures for data collection and data analysis within the prototypical framework as mentioned in the studies above. The participants of the study were undergraduate male and female students taking courses in psychology at the State University of New York, Buffalo. The results supported the conceptual basis and the prototypical structure of forgiveness. Additionally, the results showed that there was a correlation between men's and women's ratings.

Weiser, et al., (2014) conducted a study to check whether or not the concept of "infidelity" has a prototypical structure and whether or not laypeople have a similar conceptualization of it. Similar to several studies in this domain, the study relied on the prototypical analysis of concepts by carrying out four experiments. The first experiment focused on generating features of infidelity. In the second study, participants were asked to rank the prototypicality of the generated features. The third study focused on recall memory of features of the infidelity. Finally a group of participants generated narratives about infidelity. Because the researchers sought also to investigate the impact of gender on the prototypical analysis, the sample consisted of 147 males and 289 females, with a total number of 436 participants. The participants were able to generate and rate the centrality of features of this concept. Therefore, such results confirmed that infidelity is prototypically structured. Additionally, it was found that the degree of features centrality positively influenced the subjects' behavior in the recall memory and narrative tasks. Finally, the results of the second task (the prototypical ratings of features) revealed that females were more active than males in determining which features of infidelity are central and what are peripheral. 
By and large, based on the discussion above, most studies regarding the prototypical structure of concrete and abstract concepts were conducted in Western cultures. Thus, the present study is being conducted as a reaction to the paucity of studies within the prototype framework in the Arab region, in general, and in Jordan, in particular. This study aims to enrich the literature related to the prototype theory by providing insights into new cultures such as the Arab Jordanian culture. It explores the impact of culture on the conceptualization of some concrete and abstract concepts by investigating two diverse cultures, the Jordanian and the American culture.

\section{Methodology}

\subsection{Population and Sample of the Study}

Generally, the targeted population of the current study consists of undergraduate Jordanian and American students at Amman Arab University, Jordan, and at Duke University, USA. The present study includes two tasks. 117 students completed the first task (the examples and features generating): 68 Jordanian males and females and 49 American males and females. 157 students participated in the second task (the prototypicality ratings), the Jordanian sample consisted of 85 students (40 males and 45 females) and the American sample was comprised of 72 students ( 35 males and 37 females).

\subsection{Instruments and Procedures}

Two instruments were employed to achieve the purpose of this study.

\subsubsection{Task 1: Free Listing of Examples and Features}

This task is adapted from Fehr \& Russell (1984). In this task, participants were asked to provide all the possible examples and features that come to their mind when they hear or use the concepts freedom and drinks. For example, if participants were given a blank sheet of paper with the concept "pets" written on the top, they would list some examples as members of this concept such as dogs, cats, hamsters and rats. Besides, they would also provide some related features of the concept "pets" such as cute, lovely, friendly, petting, and so on.

The instrument is divided into three parts. The first part asks the participants to provide some biographical information. The second part presents some information and instructions about the nature and the purpose of the study. The third one includes the two concepts, each of which is written on the top of a blank sheet of paper to leave a suitable place for the participants to freely provide their answers. A version of this task was translated into Arabic for Jordanian participants. In order to collect the responses readily and make the task easier for the American participants, a soft copy of the instrument was developed on one of the surveys' services site, namely Survey planet (https://s.surveyplanet.com/iFurN7BcS). This survey link was sent to a mediator, who is a Jordanian professor at Duke University, and in turn he sent the link to his students.

After receiving the responses, the generated examples and the semantic features of each concept were carefully investigated, grouped and classified. For the sake of clarity and simplicity and to avoid repetition and redundancy, the various syntactic and morphological 
forms of the same response and synonymous responses were approached as one response. For example, the responses happiness, happy, being happy and feel happy were treated as one response which is "happiness." After that, the answers of each concept were counted based on their frequencies and percentages among the participants' responses. The purpose of identifying the frequency and percentage of the response provided by both Jordanians and Americans is to highlight the differences and similarities that may result from the cultural differences. The data collected in this task will be used as input in the categorization process as we will see in task 2 (The Prototypicality Ratings).

\subsubsection{Task 2: The Prototypicality Ratings}

In this task, the participants were asked to categorize the collected examples and semantic features according to the extent to which these examples and features represent the concept they belong to. This process is dependent on the notion of "graded membership," which is one of the basic principles of the prototype theory. For example, if we asked a group of participants to categorize a set of members belonging to the category "pets" such as cats, dogs, rabbits, parrots, turtles and snakes, some participants would categorize cats and dogs as very good examples of the concept "pets", rabbits and parrots as moderate examples, and turtles and snakes as very poor example. Other participants may have a different categorization system.

To achieve the purpose of this task, a questionnaire of 6-point scale (adapted from Fehr \& Russell, 1984) was developed. The distribution of the values according to this scale ranges from 1 to 6 as follow: 1-very poor example of the concept, 2-poor, 3-fairly poor, 4-fairly good, 5- good and 6-very good. The questionnaire consists of three parts. The first part seeks biographical information. The second part provides some information about the nature and the purpose of the study as well as some instructions for participants. The third includes two sub-parts; each part represents one of the two concepts with its features and examples. The responses were provided based on the participants' first impression. A version of this instrument was translated into Arabic for Jordanians. As for Americans, the researcher created a link including the instrument on "Survey Monkey," an online survey site, (https://www.surveymonkey.com/r/N8Q6GGM).

As mentioned in the previous section, the results of the first task form the input of task two. In this regard, it might be worthy to illustrate some points. First, after collecting and analyzing the results in the first task in terms of frequency and percentages, the researcher had only chosen twenty-one features and examples from each concept's list to include in task two; twenty-one items for each concept. Second, the basis on which the twenty-one items were selected was as follows: seven items with high frequency, seven with moderate frequency and seven with low frequency. Finally, the reason for this reduction is to make the job easier for the participants during taking into consideration the length of the instrument and the time needed to complete it. The idea of reducing the number of the items and the basis of choosing them to be investigated in this task was also adopted in Fehr and Russell's study (1984). 


\subsection{Validity of the Instruments}

Although the instruments are already used in some studies, the researcher followed some steps in order to ensure the validity of the instruments. In the first step, a list of experts, who are professors of linguistics in different universities in Jordan and abroad, were asked to evaluate the instruments and to provide their feedback. The reviewers' comments tackled the form of the questionnaire, the structure of the items, and the explanatory instructions that should be included for the participants in each of these instruments. The second one, the researcher asked a native speaker of American English, who is a professor of applied linguistics at Clarion University of Pennsylvania, to review the instruments in order to make it more appropriate to the American participants. Finally, professors of Arabic language were asked to review the Arabic versions of the instruments to make them more formal and suitable. All the comments and observations were taken in to consideration.

\subsubsection{The Reviewers' Comments on the 1st Instrument: Examples and Features Listing}

For the first instrument, all the evaluators confirmed the clarity and the validity of this instrument as a tool to collect examples and features of the target concepts. Furthermore, a pretest procedure proved that this instrument is a valid means to achieve its anticipated purpose.

3.3.2 The Reviewers' Comments on the 2nd Instrument: The Prototypical Rating of Examples and Features

In general, there was a consensus among the members of the jury list on the authenticity of the second instrument employed for the prototypical rating process. However, the instrument has received noticeable improvement based on the valuable feedback provided by some evaluators. Some of the evaluators confirmed the necessity of including some explanatory examples to make the task easier and clearer for the participants.

A professor from Clarion University of Pennsylvania, who is a native speaker of American English, provided helpful notes aiming to make this instrument suitable to the American participants. For example, he recommended using the word 'revitalizing' or 'refreshing' instead of using the word 'revivification', and to use the phrase 'moistening lips/ throat' instead of using the word 'moistening' alone. This is because, as he explained, it might be understood inappropriately in American English if they are used alone. Additionally, the professor also suggested that it is better to exclude the question which involves identifying gender. That is, some Americans have very strong opinions on gender these days; some view traditional gender identification as important and others find it necessary to not align themselves with stereotypes. But because gender is needed as independent variable in a future study related to the present study, it cannot be abandoned.

\subsection{Data Analysis Procedures}

To achieve the goals of the present study, a triangulated data analysis procedure was followed, using quantitative and qualitative methods. In the quantitative analysis, two statistical tests were used to answer the questions of the study. Descriptive statistics (frequencies and 
percentages) were used to answer the first question, and a t-test was used to answer the second question. As for the qualitative analysis, a discussion of the findings for each research question was provided.

\section{Findings and Discussions}

4.1 Findings Related to the First Research Question Which Concerns the Impact of the Cultural Difference on Generating Examples and Features

This task can be referred to as the scouting task aiming at eliciting the required semantic features and examples for the concepts "freedom" and "drinks." In other words, instead of imposing the examples or features of the target concepts on the participants, the participants were given the chance to freely list whatever examples or features of the target concepts that comes to their minds. So, the current task seeks to investigate the effect of the cultural difference between Jordanians and Americans on generating the semantic examples and features for each of the target concepts. This section is divided into two parts. The first part examines the findings from the lists generated by participants' examples and features of the abstract concept "freedom." The second part examines the findings from the lists generated by participants' examples and traits of the concrete concepts "drinks."

\subsubsection{Findings Related to the Concept of "Freedom"}

Table 1. Generating features and examples for the concept "freedom"

\begin{tabular}{|c|c|c|c|c|c|c|c|c|}
\hline \multirow[b]{2}{*}{ No } & \multicolumn{4}{|c|}{ Americans' responses } & \multicolumn{4}{|c|}{ Jordanians' responses } \\
\hline & Items & $\mathrm{F}$ & $\%$ & Rank & Items & $\mathrm{F}$ & $\%$ & Rank \\
\hline 1 & Free choice & 20 & $7 \%$ & 1 & Free choice & 39 & $10 \%$ & 1 \\
\hline \multirow[t]{2}{*}{2} & Chains being & & & & Chains being & & & \\
\hline & broke & 19 & $6 \%$ & 2 & broke & 17 & $4 \%$ & 7 \\
\hline 3 & Struggle & 15 & $5 \%$ & 3 & Struggle & 27 & $7 \%$ & 3 \\
\hline 4 & Free speech & 14 & $5 \%$ & 4 & Free speech & 30 & $8 \%$ & 2 \\
\hline 5 & America & 13 & $4 \%$ & 5 & & & & \\
\hline 6 & $\begin{array}{l}\text { Expressing } \\
\text { feelings }\end{array}$ & 13 & $4 \%$ & 6 & $\begin{array}{l}\text { Expressing } \\
\text { feelings }\end{array}$ & 10 & $3 \%$ & 16 \\
\hline \multirow[t]{2}{*}{7} & Ability to & & & & Ability to travel & & & \\
\hline & travel freely & 12 & $4 \%$ & 7 & freely & 14 & $4 \%$ & 10 \\
\hline 8 & Liberty & 12 & $4 \%$ & 8 & Liberty & 19 & $5 \%$ & 5 \\
\hline 9 & Rights & 12 & $4 \%$ & 9 & Rights & 16 & $4 \%$ & 9 \\
\hline 10 & Flying & 11 & $4 \%$ & 10 & Flying & 1 & $0 \%$ & 39 \\
\hline \multirow[t]{2}{*}{11} & Expressing & & & & Expressing & & & \\
\hline & opinions & 11 & $4 \%$ & 11 & opinions & 23 & $6 \%$ & 4 \\
\hline 12 & Happiness & 11 & $4 \%$ & 12 & & & & \\
\hline 13 & Independence & 10 & $3 \%$ & 13 & Independence & 17 & $4 \%$ & 8 \\
\hline 14 & Anti-racism & 9 & $3 \%$ & 14 & Anti-racism & 12 & $3 \%$ & 13 \\
\hline 15 & $\begin{array}{l}\text { Developed } \\
\text { countries }\end{array}$ & 8 & $3 \%$ & 15 & & & & \\
\hline
\end{tabular}




\begin{tabular}{|c|c|c|c|c|c|c|c|c|}
\hline 16 & Press & 7 & $2 \%$ & 16 & Press & 13 & $3 \%$ & 11 \\
\hline 17 & Safety & 7 & $2 \%$ & 17 & Safety & 2 & $1 \%$ & 32 \\
\hline 18 & Strength & 7 & $2 \%$ & 18 & Strength & 11 & $3 \%$ & 15 \\
\hline 19 & Carelessness & 6 & $2 \%$ & 19 & Carelessness & 1 & $0 \%$ & 35 \\
\hline 20 & Election & 6 & $2 \%$ & 20 & Election & 11 & $3 \%$ & 14 \\
\hline 21 & $\begin{array}{l}\text { Using social } \\
\text { media }\end{array}$ & 6 & $2 \%$ & 21 & $\begin{array}{l}\text { Using } \\
\text { media }\end{array}$ & 13 & $3 \%$ & 12 \\
\hline 22 & Life & 5 & $2 \%$ & 22 & Life & 3 & $1 \%$ & 26 \\
\hline 23 & $\begin{array}{l}\text { Spending } \\
\text { money }\end{array}$ & 5 & $2 \%$ & 23 & & & & \\
\hline 24 & $\begin{array}{l}\text { Against } \\
\text { corruption }\end{array}$ & 4 & $1 \%$ & 24 & $\begin{array}{l}\text { Against } \\
\text { corruption }\end{array}$ & 5 & $1 \%$ & 22 \\
\hline 25 & Democracy & 4 & $1 \%$ & 25 & Democracy & 6 & $2 \%$ & 20 \\
\hline 26 & Love & 4 & $1 \%$ & 26 & Love & 1 & $0 \%$ & 42 \\
\hline 27 & No study & 4 & $1 \%$ & 27 & No study & 5 & $1 \%$ & 44 \\
\hline 28 & Pride & 4 & $1 \%$ & 28 & Pride & 1 & $0 \%$ & 46 \\
\hline 29 & Unity & 4 & $1 \%$ & 29 & Unity & 1 & $0 \%$ & 48 \\
\hline 30 & Flag & 3 & $1 \%$ & 30 & & & & \\
\hline 31 & Humanity & 3 & $1 \%$ & 31 & Humanity & 1 & $0 \%$ & 40 \\
\hline 32 & No stress & 3 & $1 \%$ & 32 & No stress & 3 & $1 \%$ & 27 \\
\hline 33 & $\begin{array}{l}\text { Political } \\
\text { figures }\end{array}$ & 3 & $1 \%$ & 33 & & & & \\
\hline 34 & $\begin{array}{l}\text { Religious } \\
\text { freedom }\end{array}$ & 3 & $1 \%$ & 34 & Religious freedom & 10 & $3 \%$ & 17 \\
\hline 35 & Running & 3 & $1 \%$ & 35 & & & & \\
\hline 36 & $\begin{array}{l}\text { Statue of } \\
\text { liberty }\end{array}$ & 3 & $1 \%$ & 36 & & & & \\
\hline 37 & Change & 2 & $1 \%$ & 37 & Change & 1 & $0 \%$ & 37 \\
\hline 38 & $\begin{array}{l}\text { Confederate } \\
\text { flag }\end{array}$ & 2 & $1 \%$ & 38 & & & & \\
\hline 39 & Nature & 2 & $1 \%$ & 39 & Nature & 1 & $0 \%$ & 43 \\
\hline 40 & Palestine & 2 & $1 \%$ & 40 & Palestine & 1 & $0 \%$ & 45 \\
\hline 41 & Variety & 2 & $1 \%$ & 41 & Variety & 4 & $1 \%$ & 24 \\
\hline 42 & Abundant & 1 & $0 \%$ & 42 & & & & \\
\hline 43 & Education & 1 & $0 \%$ & 43 & & & & \\
\hline 44 & Ignorance & 1 & $0 \%$ & 44 & & & & \\
\hline 45 & Justice & 1 & $0 \%$ & 45 & Justice & 1 & $0 \%$ & 41 \\
\hline 46 & Not America & 1 & $0 \%$ & 46 & & & & \\
\hline 47 & Commitment & 1 & $0 \%$ & 47 & Commitment & 6 & $2 \%$ & 19 \\
\hline 48 & Shouting & 1 & $0 \%$ & 48 & & & & \\
\hline 49 & Spectrum & 1 & $0 \%$ & 49 & & & & \\
\hline 50 & Subjective & 1 & $0 \%$ & 50 & & & & \\
\hline
\end{tabular}




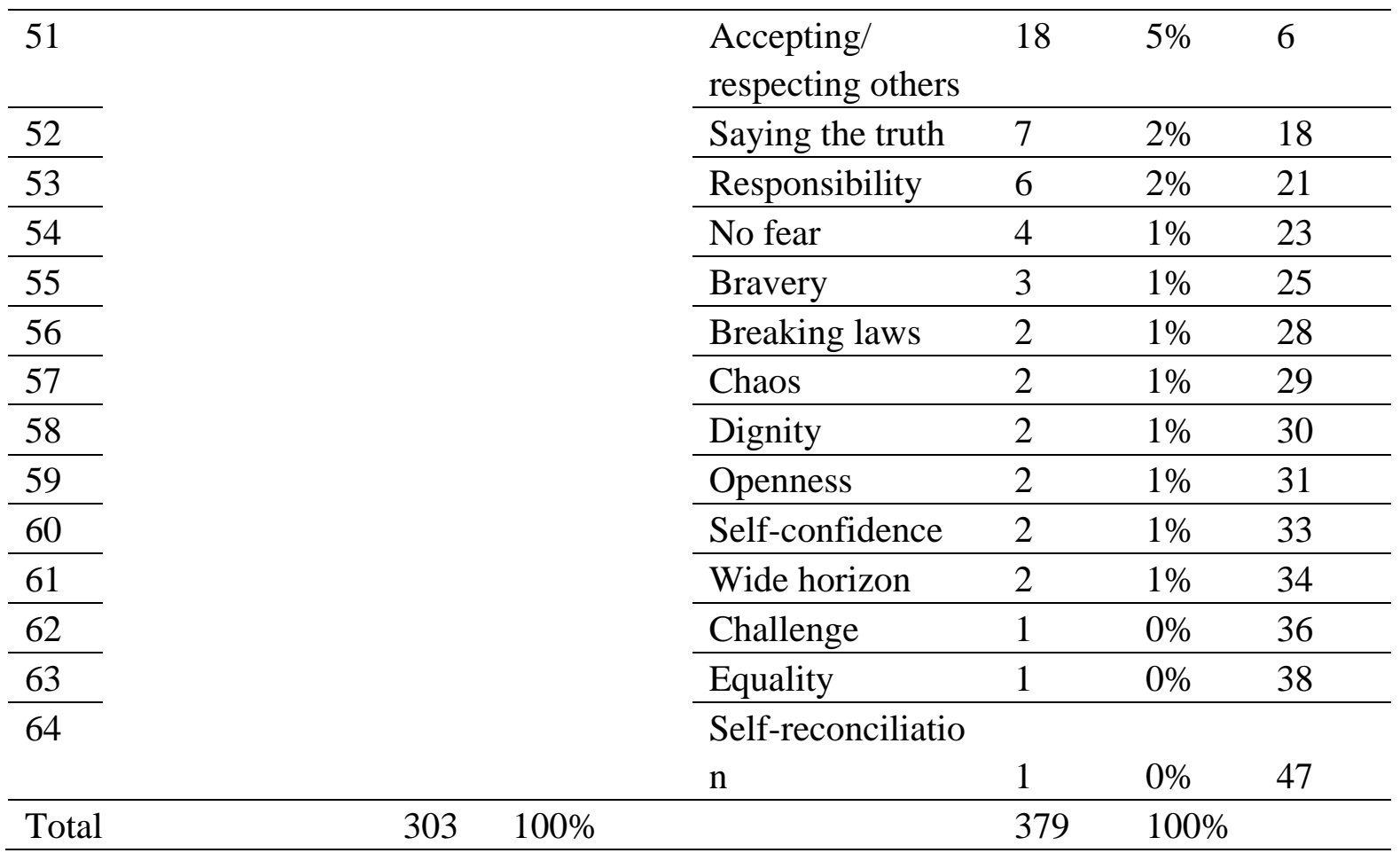

Note: Frequencies and percentages of each item generated for the concept of "freedom"

When analyzing Table 1, we observe some important findings about the concept "freedom." Firstly, the examples free choice, chains being broke and struggle occupy the first ranks among the Americans' responses in term of frequency, whereas free choice, free speech and struggle are the most frequent examples for the same concept among Jordanians' responses. Secondly, with respect to the least frequent examples and features in the generated lists, Jordanians regard unity, self-reconciliation, pride, Palestine, no study, nature, love, justice, humanity, flying, equality, challenge, change and carelessness as the least examples of "freedom." Americans, on the other hand consider abundant, education, ignorance, justice, not America, commitment, shouting, spectrum and subjective as the least good examples of "freedom." The explanations are provided below.

Finally, Table 1 shows examples and features of the concept of "freedom" that are exclusively provided by each participating group. For example, Americans listed items that were not provided by Jordanians, such as America, happiness, spending money, flag, running, statue of liberty, confederate flag, developed countries, abundant, education, ignorance, not America, and shouting. Differently, Jordanians provided their own distinctive examples and features of the concept of "freedom," such as accepting and respecting others, saying the truth, responsibility, no fear, bravery, breaking laws, chaos, dignity, openness, self-confidence, wide horizon, challenge, equality, and self-reconciliation.

Although it is challenging to interpret the way Americans and Jordanians understand the concept of "freedom," the findings suggest some ideas that may help to account for the difference in their responses. It is important to state here that the researcher interviewed some Americans, in order to come up with suitable explanations for the differing result. According to some American informants, it might be said that political figures or symbols and political 
monuments are factors, among others, that may affect the listing process by the Americans. For example, they listed the examples flag, statue of liberty and confederate flag as examples of "freedom." In comparison to Jordanians, it seems that the American people have more freedom to declare their political and party affiliations. In a different way, the examples listed by the Jordanian participants suggest that they might be affected by the ethical aspect, which is usually derived from religious beliefs and social traditions. Therefore, it is normal to find items such as accepting and respecting others, saying the truth, responsibility, self-reconciliation, and dignity as examples of "freedom" among the responses of Jordanians. Further, some Jordanians might also be influenced by the political status and social aspect. Consequently, some Jordanians may regard features such as no fear, bravery, self-confidence, challenge, and equality as a reaction against the inequality of social, occupational, and political rights. Finally, for other Jordanians, "freedom" is not always favorable, as it is something that can bring anarchy; thus, examples such as braking laws and chaos were found among their responses.

\subsubsection{Findings and Discussions Related to the Concept of "Drinks"}

Table 2. Generating features and examples for the concept "drinks"

\begin{tabular}{|c|c|c|c|c|c|c|c|c|}
\hline \multirow[b]{2}{*}{ No } & \multicolumn{4}{|c|}{ Americans' responses } & \multicolumn{4}{|c|}{ Jordanians' responses } \\
\hline & Items & $\mathrm{F}$ & $\%$ & Rank & Items & $\mathrm{F}$ & $\%$ & Rank \\
\hline 1 & Alcohol & 55 & $19 \%$ & 1 & Alcohol & 6 & $2 \%$ & 13 \\
\hline 2 & Water & 32 & $11 \%$ & 2 & Water & 32 & $12 \%$ & 3 \\
\hline 3 & Coffee & 22 & $8 \%$ & 3 & Coffee & 38 & $14 \%$ & 1 \\
\hline 4 & Hangout & 21 & $7 \%$ & 4 & & & & \\
\hline 5 & Juice & 19 & $7 \%$ & 5 & Juice & 33 & $12 \%$ & 2 \\
\hline 6 & Soda & 19 & $7 \%$ & 6 & Soda & 21 & $8 \%$ & 6 \\
\hline 7 & Tea & 17 & $6 \%$ & 7 & Tea & 26 & $10 \%$ & 4 \\
\hline \multirow[t]{2}{*}{8} & Time & & & & Time & & & \\
\hline & friends & 13 & $5 \%$ & 8 & friends & 8 & $3 \%$ & 12 \\
\hline 9 & Fruit cocktail & 12 & $4 \%$ & 9 & Fruit cocktail & 23 & $9 \%$ & 5 \\
\hline 10 & Having party & 12 & $4 \%$ & 10 & Having party & 1 & $0 \%$ & 20 \\
\hline 11 & Hangover & 11 & $4 \%$ & 11 & & & & \\
\hline 12 & Happiness & 10 & $4 \%$ & 12 & Happiness & 4 & $1 \%$ & 15 \\
\hline 13 & Thirst & 10 & $4 \%$ & 13 & & & & \\
\hline 14 & Milk & 8 & $3 \%$ & 14 & Milk & 15 & $6 \%$ & 7 \\
\hline 15 & Beverage & 5 & $2 \%$ & 15 & Beverage & 6 & $2 \%$ & 14 \\
\hline 16 & Family time & 5 & $2 \%$ & 16 & Family time & 9 & $3 \%$ & 10 \\
\hline 17 & Relaxation & 5 & $2 \%$ & 17 & Relaxation & 10 & $4 \%$ & 9 \\
\hline 18 & Dinner time & 3 & $1 \%$ & 18 & & & & \\
\hline 19 & Ice & 3 & $1 \%$ & 19 & & & & \\
\hline 20 & Study time & 3 & $1 \%$ & 20 & & & & \\
\hline 21 & & & & & Herbal drinks & 12 & $4 \%$ & 8 \\
\hline 22 & & & & & Energy drinks & 8 & $3 \%$ & 11 \\
\hline
\end{tabular}




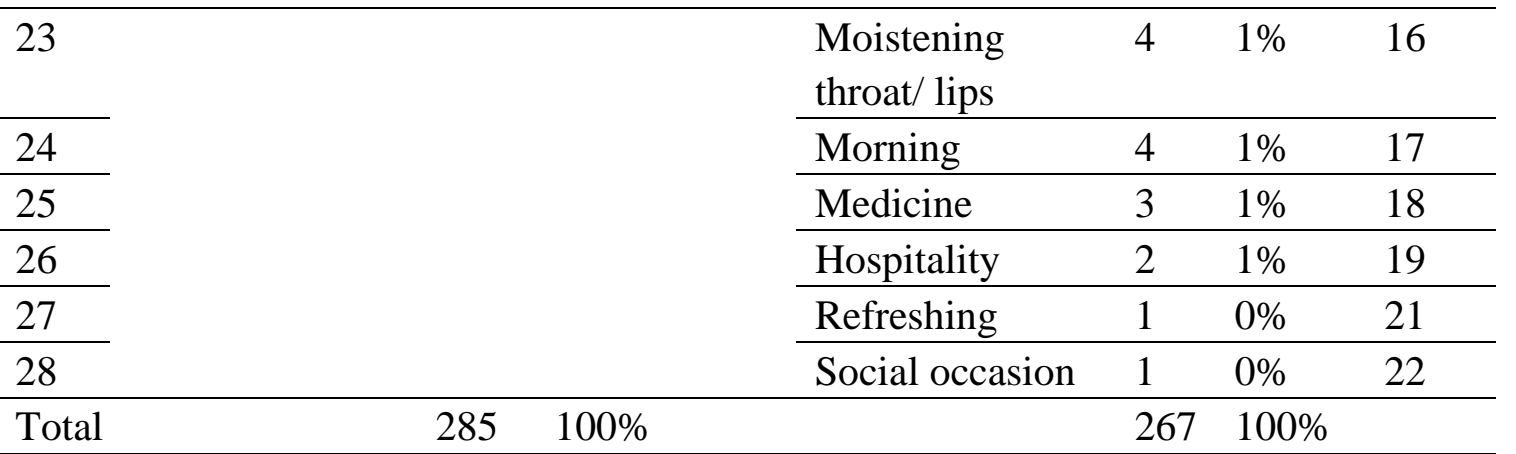

Note: Frequencies and percentages of each item generated for the concept of "drinks"

A general look at Table 2 leads us to observe that, on average, Americans are more active in responding to the concept of "drinks" than Jordanians. Table 2 shows that the most frequent examples of the concept "drinks" among Americans are alcohol, water and coffee, whereas the most frequent ones among Jordanians are coffee, juice and water. Additionally, Table 2 also indicates that Americans and Jordanians are different in terms of the exclusive listing of some examples and traits by each group. For example, Americans generated examples that were not mentioned by Jordanians at all such as hangout, thirst, hangover, ice, dinner time and study time. Conversely, Jordanian provided the following examples and traits: herbal drinks, energy drinks, moistening throat/ lips, morning and refreshing, medicine, hospitality and social occasions.

Generally speaking, it can be inferred from the generated examples and features of drinks that both American and Jordanian participants listed the most common types of drinks existing in their societies. Some of these types seem to be universal; they are found in different cultures around the world, such as water, coffee, tea, juice, and soda. Other types and features of drinks might be tied to the mores of the religions and societies. For instance, as I was told by some American informants, the example alcohol along with the features hangout and hangover may suggest that Americans, especially when they get to the later teen years (young adulthood), have the feeling to be free and independent. Additionally, America is a secular country and its people are generally more liberal than Jordanians. On the other hand, the examples herbal drinks and medicine, which are found among the Jordanians' responses, might be related to the Jordanian cultural heritage where different types of herbs, such as sage, thyme, anise, chamomile etc., are widely preferred and used by Jordanians more than Americans, as a way to treat illness (i.e., traditional or alternative medicine), respectively. Finally, herbal drinks are, in fact, among the list of beverages that Jordanians usually drink, especially during cold and flu season.

To conclude, it can be said that the cultural difference between Americans and Jordanians affects the process of examples and features listing. The most influential aspects of culture that played a role in this process are the societal aspect, the geographical aspect and everyday life experiences, including political as well as family relationships and activities. The differences in the generating process appear in the presence and absence of some items in each sample's list and in the frequency of mentioning the shared items. These findings support Cruse's (2004) assumption that daily-life experiences affect the way we understand the world and shape the 
meaning of the world's concepts. Once again, daily-life experiences are how people, who live in one area, think, feel, act, etc., on a daily basis. Daily-life experiences are always considered starting points to socio-cultural studies.

\subsection{Findings and Discussions of the Second Research Question Which Concerns the Impact of} the Cultural Differences on the Prototypicality Ratings

This part of the study explores whether or not cultural differences affect the way Jordanians and Americans rate the prototypicality of some examples and features of freedom and drinks, on a 6-point scale. To achieve this purpose, a T-test was used to investigate the difference between the means of responses of each participating group. This section is divided into two parts: the first part concerns findings related to the abstract concept "freedom," whereas the second part discusses the findings related to the concrete concept "drinks."

\subsubsection{Findings Discussions Regarding the Concept of "Freedom"}

Table 3. The result of the prototypicality ratings of the items that belong to "freedom"

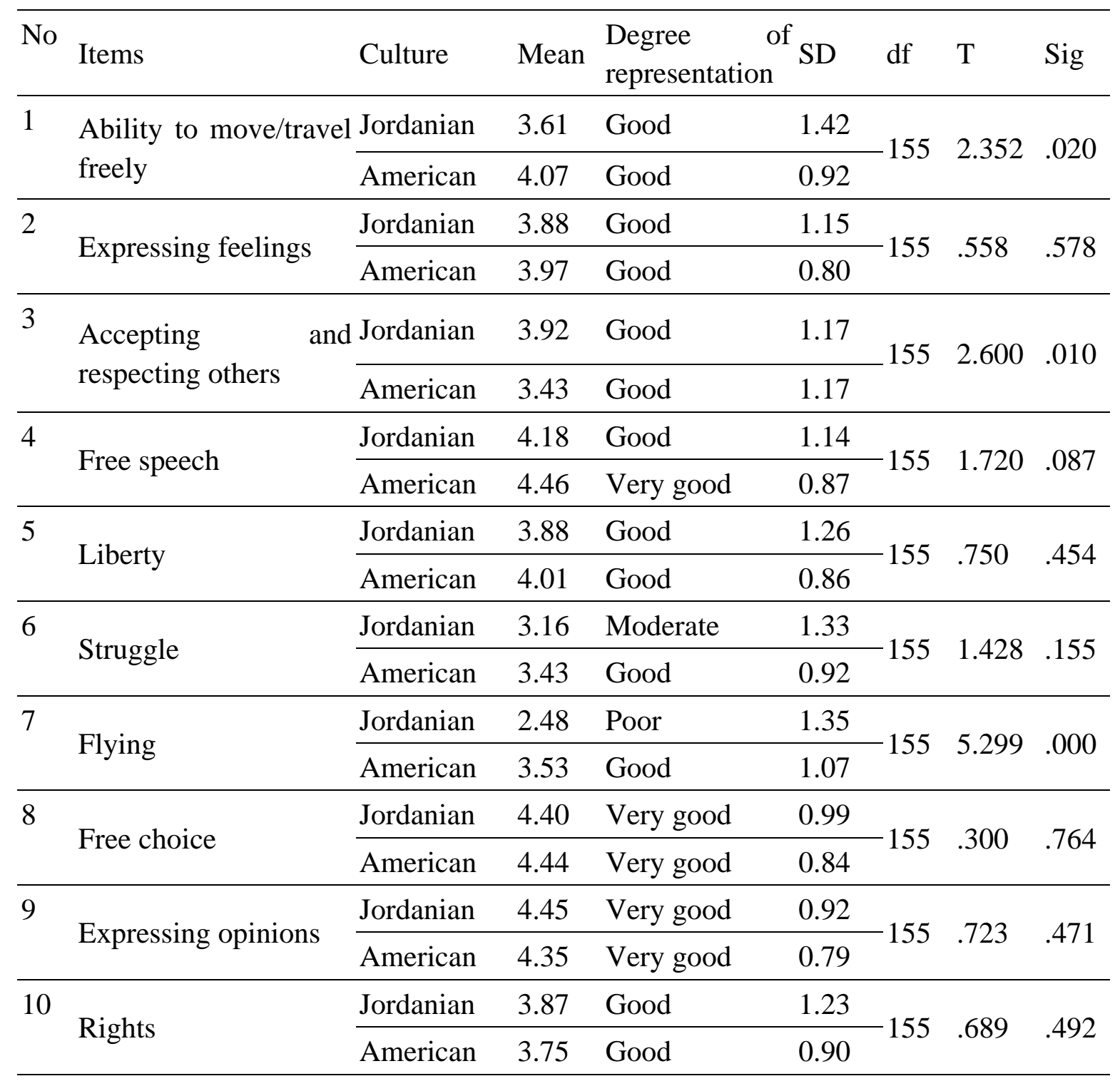




\begin{tabular}{|c|c|c|c|c|c|c|c|}
\hline \multirow[t]{2}{*}{11} & \multirow{2}{*}{ Chaos } & Jordanian & 2.04 & Poor & 1.26 & \multirow{2}{*}{2.746} & \multirow{2}{*}{.007} \\
\hline & & American & 2.57 & Poor & 1.16 & & \\
\hline \multirow[t]{2}{*}{12} & \multirow{2}{*}{ Election } & Jordanian & 2.92 & Moderate & 1.41 & \multirow{2}{*}{.976} & \multirow{2}{*}{.331} \\
\hline & & American & 3.11 & Moderate & 1.00 & & \\
\hline \multirow[t]{2}{*}{13} & \multirow{2}{*}{ Press } & Jordanian & 2.88 & Moderate & & \multirow{2}{*}{.814} & \multirow{2}{*}{.417} \\
\hline & & American & 3.04 & Moderate & 1.08 & & \\
\hline \multirow[t]{2}{*}{14} & \multirow{2}{*}{ Using social media } & Jordanian & 3.27 & Moderate & \multirow{2}{*}{-155} & \multirow{2}{*}{.707} & \multirow{2}{*}{.480} \\
\hline & & American & 3.14 & Moderate & & & \\
\hline \multirow[t]{2}{*}{15} & \multirow{2}{*}{ Shouting } & Jordanian & 1.91 & Poor & 1.11 & \multirow{2}{*}{3.090} & \multirow{2}{*}{.002} \\
\hline & & American & 2.46 & Poor & 1.13 & & \\
\hline \multirow[t]{2}{*}{16} & \multirow{2}{*}{ Dignity } & Jordanian & 3.52 & Good & & \multirow{2}{*}{.395} & \multirow{2}{*}{.693} \\
\hline & & American & 3.44 & Good & & & \\
\hline \multirow[t]{2}{*}{17} & \multirow{2}{*}{ Strength } & Jordanian & 3.35 & Moderate & & \multirow{2}{*}{.351} & 726 \\
\hline & & American & 3.42 & Good & & & .120 \\
\hline 18 & Develoned countriec & Jordanian & 3.45 & Good & 1.45 & 1820 & 060 \\
\hline & Doveropecucoumtics & American & 3.07 & Moderate & 1.07 & 1.02 ( & (00 \\
\hline 19 & Indenendence & Jordanian & 3.81 & Good & 1.23 & 661 & 510 \\
\hline & 1пиерепिене & American & 3.69 & Good & 0.94 & - .001 & . \\
\hline 20 & Anti racism & Jordanian & 3.60 & Good & 1.22 & 1100 & 232 \\
\hline & Hiti-1actsm & American & 3.81 & Good & 0.87 & 1.13 נ & .252 \\
\hline 21 & hoing hrol & Jordanian & 3.60 & Good & 1.34 & 037 & 301 \\
\hline & CHans deng oroke & American & 3.79 & Good & 0.89 & 1.051 & 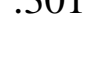 \\
\hline
\end{tabular}

Note: Employing T-test to investigate the differences between Jordanians and Americans in categorizing the items of the concept of "freedom"

The findings in Table 3 show that the descriptive statistics of the participants' responses to the concept of "freedom" ranged from 1.91 to 4.45 by Jordanians and from 2.46 to 4.46 by Americans. According to the table, Jordanians categorize expressing opinions and free choice as very good examples of "freedom." Americans categorize free speech (as Americans have more freedom than Jordanians to declare their political and ideological affiliations, and to criticize political figures), free choice and expressing opinions as very good examples represent "freedom." As for the least representative examples of "freedom," Jordanians and Americans classify shouting, chaos and flying as the poorest examples of "freedom." Table 3 also indicates that there are statistically significant differences in five examples, namely, accepting and respecting others in favor of Jordanians and the examples ability to movel travel freely, flying, chaos and shouting in favor of Americans. Finally, Table 3 indicates that there are no statistically significant differences in the other examples and features of the concept of "freedom." 
The great consensus among Jordanians and Americans on rating the prototypicality might be imputed to the globalization and the spread of slogans, speeches and experiences of freedom from all around the world. The differences between the cross-cultural groups might be explained in several ways. For instance, what led the Jordanian participants to regard accepting and respecting others as good example might be the Arabic Islamic heritage. That is, the Arabic Islamic heritage prompts accepting and respecting others regardless of their religious, political, social or economic status. On the other hand, the findings indicate that American participants have priority over Jordanians in classifying the examples ability to movel travel freely, flying, shouting and chaos. This might be attributed to the fact that the US is a vast country, where Americans travel long distances for work or for visiting families. Furthermore, Americans may have more economic power to travel and fly and may have more freedom to shout and declare whatever they want.

\subsubsection{Findings and Discussions Regarding to the Concept of "Drinks"}

Table 4. The result of the prototypicality ratings of the items that belong to "drinks"

\begin{tabular}{|c|c|c|c|c|c|c|c|c|}
\hline No & Items & Culture & Mean & $\begin{array}{l}\text { Degree of } \\
\text { representation }\end{array}$ & SD & Df & $\mathrm{T}$ & Sig \\
\hline \multirow[t]{2}{*}{1} & \multirow{2}{*}{ Alcohol } & Jordanian & 2.00 & Poor & 1.35 & \multirow{2}{*}{-155} & \multirow{2}{*}{8.605} & \multirow{2}{*}{.000} \\
\hline & & American & 3.89 & Good & 1.39 & & & \\
\hline \multirow[t]{2}{*}{2} & \multirow{2}{*}{ Water } & Jordanian & 4.14 & Good & 1.15 & \multirow{2}{*}{-155} & \multirow{2}{*}{.517} & \multirow{2}{*}{.606} \\
\hline & & American & 4.22 & Very good & 0.74 & & & \\
\hline \multirow[t]{2}{*}{3} & \multirow{2}{*}{ Relaxation } & Jordanian & 2.95 & Moderate & 1.36 & \multirow{2}{*}{-155} & \multirow{2}{*}{.799} & \multirow{2}{*}{.426} \\
\hline & & American & 3.11 & Moderate & 1.07 & & & \\
\hline \multirow[t]{2}{*}{4} & \multirow{2}{*}{ Coffee } & Jordanian & 4.19 & Good & 1.09 & \multirow{2}{*}{-155} & \multirow{2}{*}{.648} & \multirow{2}{*}{.518} \\
\hline & & American & 4.29 & Very good & 0.88 & & & \\
\hline \multirow[t]{2}{*}{5} & \multirow{2}{*}{ Hangout } & Jordanian & 2.13 & Poor & 1.33 & \multirow{2}{*}{-155} & \multirow{2}{*}{6.344} & \multirow{2}{*}{.000} \\
\hline & & American & 3.33 & Moderate & 0.99 & & & \\
\hline \multirow[t]{2}{*}{6} & \multirow{2}{*}{$\begin{array}{l}\text { Moistening throat/ } \\
\text { lips }\end{array}$} & Jordanian & 3.60 & Good & 1.30 & \multirow{2}{*}{-155} & \multirow{2}{*}{1.551} & \multirow{2}{*}{.123} \\
\hline & & American & 3.31 & Moderate & 1.03 & & & \\
\hline \multirow[t]{2}{*}{7} & \multirow{2}{*}{ Having a party } & Jordanian & 2.29 & Poor & 1.18 & \multirow{2}{*}{-155} & \multirow{2}{*}{3.531} & 001 \\
\hline & & American & 2.93 & Moderate & 1.05 & & & .001 \\
\hline 8 & Pefreching & Jordanian & 3.84 & Good & 1.15 & 155 & 672 & 008 \\
\hline & Кепељпाп & American & 3.36 & Moderate & 1.05 & & 2.012 & .000 \\
\hline 9 & Tan & Jordanian & 4.22 & Very good & 1.11 & 155 & 168 & 867 \\
\hline & $1 \mathrm{ed}$ & American & 4.25 & Very good & 0.82 & & .100 & .007 \\
\hline 10 & Mill & Jordanian & 3.52 & Good & 1.39 & 55 & 1702 & 075 \\
\hline & IVIIIK & American & 3.15 & Moderate & 1.11 & Jנ & 1.192 & .013 \\
\hline 11 & Soda & Jordanian & 3.84 & Good & 1.34 & 155 & .413 & .680 \\
\hline
\end{tabular}




\begin{tabular}{|c|c|c|c|c|c|c|c|}
\hline & & American & 3.75 & Good & 1.22 & & \\
\hline \multirow[t]{2}{*}{12} & \multirow{2}{*}{ Fruit cocktail } & Jordanian & 3.94 & Good & 1.14 & \multirow{2}{*}{2.874} & \multirow{2}{*}{.005} \\
\hline & & American & 3.44 & Good & 1.01 & & \\
\hline \multirow[t]{2}{*}{13} & \multirow{2}{*}{ Family time } & Jordanian & 2.69 & Moderate & 1.34 & \multirow{2}{*}{2.201} & \multirow{2}{*}{.029} \\
\hline & & American & 3.14 & Moderate & 1.17 & & \\
\hline \multirow[t]{2}{*}{14} & \multirow{2}{*}{ Juice } & Jordanian & 4.15 & Good & 1.06 & \multirow{2}{*}{.444} & \multirow{2}{*}{.658} \\
\hline & & American & 4.08 & Good & 0.87 & & \\
\hline \multirow[t]{2}{*}{15} & \multirow{2}{*}{ Time with friends } & Jordanian & 3.12 & Moderate & 1.22 & \multirow{2}{*}{2.960} & \multirow{2}{*}{.004} \\
\hline & & American & 3.61 & Good & 0.78 & & \\
\hline \multirow[t]{2}{*}{16} & \multirow{2}{*}{ Ice } & Jordanian & 3.05 & Moderate & & \multirow{2}{*}{.747} & \multirow{2}{*}{.456} \\
\hline & & American & 3.19 & Moderate & 1.00 & & \\
\hline \multirow[t]{2}{*}{17} & \multirow{2}{*}{ Herbal drinks } & Jordanian & 3.58 & Good & \multirow{2}{*}{-155} & \multirow{2}{*}{2.990} & \multirow{2}{*}{.004} \\
\hline & & American & 3.03 & Moderate & & & \\
\hline \multirow[t]{2}{*}{18} & \multirow{2}{*}{ Hangover } & Jordanian & 1.89 & Poor & \multirow{2}{*}{-155} & \multirow{2}{*}{8.722} & \multirow{2}{*}{.000} \\
\hline & & American & 3.53 & Good & & & \\
\hline 19 & Study time & Jordanian & 2.41 & Poor & 1.36 & 362 & 718 \\
\hline & 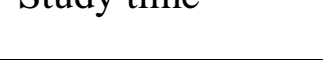 & American & 2.49 & Poor & 1.19 & & . \\
\hline 20 & Fnorau drint & Jordanian & 3.33 & Moderate & 1.34 & 1502 & 120 \\
\hline & 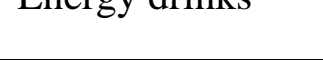 & American & 3.04 & Moderate & 0.96 & $1.02 \mathrm{~J}$ & .100 \\
\hline 21 & & Jordanian & 2.82 & Moderate & 1.36 & & \\
\hline & & American & 2.07 & Poor & 1.03 & 1 & .000 \\
\hline
\end{tabular}

Note: Employing T-test to investigate the differences between Jordanians and Americans in categorizing the items of the concept of "drinks"

As shown in Table 4, the descriptive statistics of the participants' responses toward the concept "drinks" ranged from being poor to being very good with means from 1.89 to 4.22 by Jordanians and from 2.07 to 4.29 by Americans. Based on the statistics in the table above, it is clear that Jordanians categorize tea as the best example of "drinks," whereas Americans classify coffee, tea and water as the best examples. As for the least representative examples of the concept "drinks," the means show that Jordanians categorize hangover, alcohol, hangout, party and study time as the poorest examples of "drinks," and Americans consider medicine and study time as least representative ones.

According the table above, there is a general consensus among the Jordanian and the American participants on the degree of representations of many of the examples and features of "drinks." This consensus can be attributed to the fact that these types of drinks are common in most cultures all over the world. Despite this agreement, there are still statistically significant differences in classifying some examples, as well as some features, of the concept of "drinks." Table 4 indicates clearly that there are statistically significant 
differences between Jordanians and Americans in rating the prototypicality of ten items describing drinks. For example, there are significant differences in medicine, herbal drinks, fruit cocktail and refreshing in favor of Jordanians, and in alcohol, hangover, time with friends, family time, party and hangout in favor of Americans.

Let us start the discussion with the differences in favor of Jordanians. The significant statistical differences in the items fruit cocktail and refreshing and in the items herbal drinks and medicine, which are highly correlated, might be strongly related to the Jordanians' social and alimentary mores. That is to say, more than Americans, Jordanians tend to rely heavily on many different herbs, such sage, thyme, anise, ginger, chamomile, etc., as an alternative treatment to pharmaceutical medicine. Some Jordanians believe that these medicinal drinks can be favorable alternative of the conventional medicine, especially during cold and flu season. The traditional medicine is an inherent part of the Jordanian heritage. The example fruit cocktail might also be tied to the food habits in the Jordanian society especially that juices and fruit cocktails are served in most coffee shops, juice carts, stalls, cafeterias and restaurants. Concerning the item refreshing, it might be inferred that Jordanians perceive some drinks as source of nutrition, refreshing and cooling (in hot seasons), in addition to being a medical treatment (especially during cold and flu season), as is the case with the medicinal drinks mentioned above.

With regard to the example alcohol and some items which are well-related to it, such as hangout, party, family time, time with friends and hangover, it might be said that they are tied to the mores of the American society, which is in general secular. In other words, the concept of "haram" (i.e., taboo) does not exist societally in the US as a covenant. That means what should be "forbidden" in the US does exist as a political norm but not as a social precept. Therefore, throughout US society, people can hangout and drink alcohol at parties, with families and with friends, especially during the days of weekends and holidays. Further, in the US, there is the feeling that when you get to the later teen years (young adulthood), you are free (independent, "your own person"), and that might include being allowed to have alcohol drinks and go out and to do lots of fun activities.

Generally speaking, the distribution of the items from being very poor (i.e., the least representative example of the concept) to being very good example (i.e., the most representative example of the concept) on the 6-point scale adopted in the present study supports the most fundamental principle of the prototype theory, which is "Goodness of Exemplar." That is, items belonging to a given category do not necessarily have the same status: some of these items are central prototypes of the category, some are moderate prototypes, and others are peripheral prototypes. This, in turn, contradicts the principles of the classical theory, which, as stated earlier, suggest that a category's members are of the same status. As for the relationship among the members of one category, the findings advocate for the "family resemblance" principle, in which a concept's members resembles a family's members; some are the same (in term of representation), some are less similar, and others are not similar at all. That is, when investigating the members of a certain category, we may find that some members are similar (in term of representation), some are less similar, and others are not similar at all. Finally, the prototypical rating process of the items confirms 
that each one of the concepts under investigation has a conceptual structure which is part of a general cognition process available in the minds of language speakers.

\section{Conclusions}

The findings related to the first research question showed that the cultural differences played an important role in the generating process. Culture is actually influenced by what Cruse (2004) calls "daily-life experiences," which form our conceptual structures. The cultural differences between Americans and Jordanians affected the process of generating the semantic examples and features for each concept. For example, in the features and examples list of the concept of "freedom," there were differences in twenty-nine items: fifteen in favor of Americans and fourteen in favor of Jordanians. The findings revealed that the most influential aspects of culture that affected this process were the societal aspect, the geographical aspect and everyday life experiences including political as well as family relationships and activities.

As for the second research question, the findings showed that culture played a significant role in forming the prototypical structure of the target concepts. According to the findings, it seems that the most influential aspects that contributed to forming the differences between the responses of Americans and Jordanians were the following:

- Freedom: The social and religious heritage, the political affiliations and interests, and the economic power.

- Drinks: The social and religious aspects (including social occasions and mores and Religious prohibitions) in which Jordanian societies are conservative, whereas American societies are liberal. The other aspect that affected the prototype structure of "drinks" is the alimentary habits in each community.

Finally, the distribution of the items belonging to the concepts from being a very good example to being a very poor example of the concept confirmed the prototype structures of these concepts. That means, this distribution advocates for by the legality of the prototype theory principles, such as "family resemblance," "goodness of exemplar," and "the graded membership".

\section{Recommendations}

Considering the results of the present study, the researcher proposes some recommendations for future studies in the field of cognitive semantics in general and for studies within the framework of the prototype theory in particular. The recommendations are the following:

- A promising future study could be to investigate further factors that may influence the conceptualizations of every day concepts in the language users' minds, such as gender, age, religious background, and more diverse cultures.

- The researcher also recommends including more concepts, especially abstract ones, in future studies. Abstract concepts such as infidelity and commitment seem fuzzy to most laypeople because they have no physical references in real life; they are just ideas in the minds of people.

- Additionally, the researcher proposes to adopt the prototypical view to examine the semantic relations among concepts, especially synonyms and antonyms. This would be 
achieved by examining the extent of what is called "features overlapping," where synonymous or related words are assumed to share in common plenty of features and examples. This investigation can also be obtained by considering the prototypical structure in which synonymous concepts are assumed to almost share the same central, moderate, or peripheral prototypes when it comes to the prototypicality ratings. In other words, the more the prototypical structures of concepts are similar the more they are synonymous, and vice versa.

\section{References}

Aitchison, J. (1998). Bad Birds and Better Birds: Prototype Theories. In P. Virginia, P. Clark, A. Eschhols, \& A. F. Rosa (Eds.), Language, Readings in Language and Culture (6th ed. pp. 225-239). Boston: Bedford / St. Martin's.

Ashcraft, M. H. (1978). Property norms for typical and atypical items from 17categories: A description and discussion. Memory \& Cognition, 6(3), 227-232. https://doi.org/10.3758/BF03197450

Basile, J. (2007). Prototypes in Europe and North America: How they reflect gender and cultural differences. Unpublished Master's Thesis, Karlstads University, Sweden.

Birnie-Porter, C., \& Lydon, J. (2012). A prototype approach to understanding sexual intimacy through its relationship to intimacy. Personal Relationship, 20(2), 236-258. https://doi.org/10.1111/j.1475-6811.2012.01402.x

Cruse, D. A. (2000). Aspects of the Micro-Structure of Word Meanings. In Y. Ravin, \& C. Leacock (Eds.), Polysemy: Theoretical and computational approaches (pp. 30-51). Oxford: Oxford University Press.

Cruse, D. A. (2004). Meaning in Language: An Introduction to Semantics and Pragmatics. Oxford University Press. Oxford New York.

Evans, V. (2007). A Glossary of Cognitive Linguistics. Edinburgh: Edinburgh University Press.

Evans, V., \& Green, M. (2006). Cognitive Linguistics: An Introduction. Edinburgh: Edinburgh University Press.

Fehr, B. (1986). Prototype Analysis of the Concepts of Love and Commitment. Unpublished PhD. Dissertation, University of British Colombia.

Fehr, B., \& Russell, J. A. (1984). Concept of emotion viewed from a prototype perspective. Journal of Personality and Social Psychology, 60(3), 425-438. https://doi.org/10.1037/0022-3514.60.3.425

Fehr, B., \& Sprecher, S. (2009). Prototype analysis of the concept of compassionate love. Personal Relationship, 16(3), 343-364. https://doi.org/10.1111/j.1475-6811.2009.01227.x

Fillmore, C. J. (1976). An alternative to checklist theories of meaning. Proceedings of the First Annual Meeting of the Berkeley Linguistics Society, 123-131.

Geeraerts, D. (1997). Diachronic Prototype Semantics: A Contribution to Historical Lexicology. Oxford: Oxford University Press. 


\section{Macrothink}

International Journal of Linguistics

ISSN 1948-5425

2020, Vol. 12, No. 2

Harasymchuk, C., \& Fehr, B. (2012). Development of a prototype-based measure of relational $\quad$ boredom. Personal 162-181. https://doi.org/10.1111/j.1475-6811.2011.01346.x

Kearns, J. N., \& Fincham, F. D. (2004). A prototype analysis of forgiveness. Personal and Social Bulletin, 30(7), 813-855. https://doi.org/10.1177/0146167204264237

Lakoff, G. (1987). Women, Fire, and Dangerous Things: What Categories reveal about the mind. The University of Chicago press, Chicago and London.

Lin, P. J., \& Schwanenflugel, P. (1995). Cultural familiarity and language factors in the structure of category knowledge. Journal of Cross-Cultural Psychology, 26(2), 153-168. https://doi.org/10.1177/0022022195262003

Mervis, C., \& Rosch, E. (1981). Categorization of natural objects. Ann. Rev. Psychol, 32, 89-115. https://doi.org/10.1146/annurev.ps.32.020181.000513

Neto, F., \& Mullet, E. (2014). A Prototype Analysis of the Portuguese Concept of Saudade. $\begin{array}{llll}\text { Journal of Cross-Cultural } & \text { Psychology, 45(4), } 670 .\end{array}$ https://doi.org/10.1177/0022022113518370

Padua IV, V. (1998). Concepts of emotion: Emotionness, and dimensional ratings of Italian $\begin{array}{llll}\text { emotion } \quad \text { words. } \quad \text { Cognition } & \text { 243-272. }\end{array}$ https://doi.org/10.1080/026999398379745

Saeed, J. (1997). Semantics. UK: Blackwell Publishers Ltd.

Schwanenflugel, P. J., \& Rey, M. (1986). The relationship between category typicality and concept familiarity: Evidence from Spanish- and English-speaking monolinguals. Memory and Cognition, 14(2), 150-163. https://doi.org/10.3758/BF03198375

Sprecher, S. (2009). Prototype analysis of the concept of compassionate love. Personal Relationship, 16(3), 343-364. https://doi.org/10.1111/j.1475-6811.2009.01227.x

Tamli, L. (2000). Toward a Cognitive Semantics. Cambridge, MA: MIT Press.

Tsoneva-Mathewson, S. T. (2009). Cognitive Linguistics. UK: St. Andrews University.

Wang, X. (2016). Categorization method affects the typicality effect: ERP evidence from a category-inference task. Frontiers in Psychology, 7, 1-11. https://doi.org/10.3389/fpsyg.2016.00184

Weiser, D. (2014). A prototype analysis on infidelity. Personal Relationship, 21(4), 655-675. https://doi.org/10.1111/pere.12056

\section{Copyrights}

Copyright for this article is retained by the author(s), with first publication rights granted to the journal.

This is an open-access article distributed under the terms and conditions of the Creative Commons Attribution license (http://creativecommons.org/licenses/by/4.0/) 